\title{
An Analysis of Word Meanings in English Vignettes Facing Innovative Teaching Reform
}

\author{
Dan $\mathrm{Xu}$ \\ Faculty of International Studies, Henan Normal University, Xinxiang, China \\ Email: $x_{-}$dan@foxmail.com
}

\begin{abstract}
English phrasal verbs are English verbs composed of a verb plus one or two vignettes. Its function is equivalent to a complete syntactic and semantic unit. The metacognitive theory in cognitive linguistics is applied to lexical research in applied linguistics. Promoting effects of conceptual metaphor, image schemata metaphor and conceptual metonymy consciousness in idiomatic chunk learning are proposed and confirmed through empirical research. It has been proved in practice that conceptual metaphors have cultural characteristics, that is, conceptual metaphors are not equivalent in various cultures, some conceptual metaphors are universal, and some have cultural particularities. Based on the theory of cognitive metaphors, and centering on the vignettes in phrasal verbs, starting from the spatial meaning of the vignettes, discovering their metaphorical meanings to help students better understand and use English phrasal verbs, thereby improving students' comprehensive language use ability.
\end{abstract}

Keywords: particle, metaphor theory, semantic features, teaching English

\section{Introduction}

When people learn a language, vocabulary learning is essential. Vocabulary learning is the core and most important part of language learning. McCarthy pointed out that no matter how successful the students are in learning grammar and pronunciation, it is impossible to communicate in a second language without vocabulary to express meaning. English vocabulary competence is also one of the important standards for Chinese students' English proficiency. In order to improve students' vocabulary, vocabulary learning is necessary and effective. English phrasal verbs are an important part of vocabulary and have become an independent lexical field. Therefore, the study of English phrasal verbs is an important aspect for students to learn English well.

In the process of English teaching, teachers generally believe that the difficulty in teaching vocabulary lies in the teaching of sketches. Sketches have always been difficult to break through in teaching. The problems reflected are that they have many knowledge points, take time, and are inefficient. Although many teachers have been struggling to find new teaching methods for sketch words in the teaching process, trying to find some novel, time-saving, and efficient teaching methods that enable students to truly master their usage after learning. But the situation is not ideal, and many still use traditional teaching methods. At the same time, in the process of learning vocabulary, students feel that the difficulty of learning is often difficult to master the trivial words. The problem they reflect is that the effect of repeated memory is very bad. Not only can it not help them to remember effectively, but they also have serious mismatches and improper wording when they use sketches, so it is necessary to eliminate this obstacle.

In general, English phrasal verbs are a combination of verbs and vignettes (adverbs or prepositions). They are the most common and important feature in English and the richest source of new words. Because English phrasal verbs are widely used in daily communication, they play an extremely important role in the vocabulary of English verbs. If one wants to master English fully, he must understand and master as many phrase verbs as possible. However, for students who use English as a foreign language, the study of English phrasal verbs is generally considered to be the most difficult part of the vocabulary learning field. First, phrase verbs express an integral and indivisible concept, often not simply adding together the semantics of their components, causing many difficulties in understanding. Second, phrasal verbs have rich metaphorical meanings. One phrasal verb may have multiple meanings, 
and multiple phrasal verbs may have the same or similar meanings. Third, when using phrasal verbs, they are often restricted by collocations in specific contexts.

Cognitive linguistic studies show that the different meanings of words are extended from a core meaning, and the reason for this meaning extension is the transformation of metaphor, metonymy, and image schema. These research results can be applied to the acquisition and teaching of polysemy of phrasal verbs.

In recent years, many domestic scholars and experts have applied the theory of cognitive linguistics to the empirical research of English vocabulary acquisition, and achieved good results. However, there are few studies on the acquisition of phrasal verbs, and they have the following deficiencies: These studies mainly focus on the study of phrasal verb usage by learners, and few empirical studies have been used to guide the teaching of phrasal verbs using cognitive linguistic theory; These studies focus on the analysis of the cognitive motivations between the multiple meanings of phrasal verbs. In short, the study of phrase verbs in China using cognitive linguistic theories is mainly speculative, and there are few empirical studies.

With the development of computer technology, more and more educational researchers pay attention to visual teaching. In the process of English teaching, visual teaching tools are increasingly favored by teachers and students. Visualization of English teaching can be realized through modern advanced multimedia technology, and the disadvantages of changing the traditional single teaching mode have played an extremely important role in improving the effectiveness and quality of English teaching. At the same time, it is necessary to use the research results of metaphor theory in cognitive linguistics to guide our students' empirical research on phrase verb acquisition. In teaching practice, allowing students to grasp the cognitive rationale between multiple metaphorical meanings of phrasal verbs has important theoretical and practical significance for the teaching of phrasal verbs. Therefore, this article attempts to analyze the teaching method of visual English vignette words based on metaphor theory.

\section{Overview of English Phrasal Verbs}

Phrasal verbs are also called multi-word verbs. Different linguists have different opinions on the definition of phrase verbs. "Longman Phrasal Verb Dictionary" defines that phrasal verbs are composed of two or three words, and most of them are two words. A two-word phrasal verb consists of a verb followed by an adverb or preposition (collectively called trivial words). The Longman Dictionary of Language Teaching and Applied Linguistics considers phrasal verbs to mean verb structures composed of verbs and prepositional adverbs. Now the term phrasal verb is commonly used to collectively refer to phrasal verbs, prepositional verbs, and adverbial verbs. "Oxford Advanced English-Chinese Dictionary" defines that phrasal verbs are sometimes referred to as multi-word verbs, which refer to verbs composed of two or sometimes two words. It can be seen that English phrasal verbs are English verbs composed of a verb plus one or two vignettes; they function as a complete syntactic structure and semantic unit.

\subsection{The Difference Between Phrasal Verbs and Verb Phrases}

Verb phrase is a concept in transformational grammar, which refers to the part of the sentence that contains the main verbs, prepositions, complements, and adverbs. The verb phrase is actually a free phrase. The supplements used after the head verb can be NP, AP, PP, S, and so on. Therefore, the verb phrase refers to the verb and all other subsequent components in the sentence, and its structural form is very loose and unstable. The semantics of such verb phrases are also mostly composed of simple addition and combination of the semantics of each component. However, some verb phrases are verb idioms centered on verbs. The entire phrase is like a verb and has independent lexical meaning.

According to Chomsky's transformation-generating grammar, a phrasal verb is an idiom and a relatively fixed form. It can be divided into phrasal verbs, preposition verbs, and phrase preposition verbs. Phrasal verbs can be divided into three structural forms: one is the verb adverb, the other is the verb preposition, and the third is the verb adverb. The semantics of some phrasal verbs can be inferred from their superficial meanings, but the meaning of some phrasal verbs is difficult to infer from the sum of their literal meanings. Most phrasal verbs have the characteristics of various components and can 
express different meanings in different contexts. It can be seen that although English verb phrases and phrasal verbs are different, they have overlapping parts.

\subsection{Theories of Cognitive Metaphor}

Metaphor is fundamentally a cognitive phenomenon. It is a cognitive activity in which human beings use the experience of one field to explain or understand the experience of another field. Metaphorical thinking is the only way for humans to understand things and build conceptual systems. It plays an important role as a bridge between language and cognition, and is one of the important means for us to understand the change of the world and language. On the premise that the internal structure of the target domain is consistent with the metaphor mapping, the cognitive layout of the source domain is retained, which is the image schema structure. For example, if the source domain is a container schema, the inside of the container will be mapped to the inside of the target domain, the outside to the outside of the target domain, and the edge to the edge of the target domain. Similarly, in the path schema, the starting point in the source domain is mapped to the starting point in the target domain, the end point in the source domain is mapped to the end point in the target domain, and so on. The immutability principle is actually a constraint on the mapping process. That is, the image schema structure inherent in the target domain will not be damaged. The structure of the target domain limits the possibilities for automatic mapping. For example: Life is a journey. In this metaphor, the source domain is journey and the target domain is life. The significant structural features of the source domain include: (1) travelers; (2) travel has a structure of beginning, journey, and end; and (3) various situations that may occur during travel. In the process of understanding this metaphor, various remarkable structural features of journey were systematically mapped into the field of life. Therefore, life, like journey, has a beginning and an end. In the journey of life, sometimes it can be smooth sailing, sometimes it can be full of hardships. Therefore, English has the following expression: He's gone through a lot in life. It can be seen that the meaning of metaphor depends on the meaning and structural characteristics of the source domain. In the process of metaphor understanding, the structure of the source domain is transferred to the target domain on a large scale and systematically, and becomes a part of the structure of the target domain, so the former determines the meaning of the latter. It should be noted that the so-called "invariance principle" is a relative concept, which means that some important structural relationships in the source domain are still systematically retained in the target domain. It does not mean that all features in the source domain are "mapped" into the target domain without reservation.

Closely related to the structural features and modes of action of metaphor are the dual images of metaphor. Dual images are the basic source of metaphor's vividness. From a structuralist point of view, each unit of language is in a relationship of either aggregation or combination with other words. For example, the word "drink" is in an aggregated relationship with "eat", "drink", etc., and can be replaced syntactically; it is in a combined relationship with "water", "soup", "drink", and so on. Because these relationships are relatively fixed and used frequently, a schema structure is formed in the user's brain. As soon as the keywords appear, related images appear at the same time. The so-called dual image refers to the abnormal collocation in metaphor, which not only evokes the usual association relationship and the corresponding image, but also evokes the listener's imagination of the image formed by the new combination. For example, when we hear The ship ploughed through the sea, the first thing in our minds is that a large ship sailing in the sea and a farmer is plowing the field. Then, as the speaker continued to say "through the sea", the image of a ship chopping waves in the sea quickly and hardly appeared again in our brains. Because of this dual image, metaphor has the dynamic interaction process that general language use does not have, which transfers the characteristics of things belonging to one field to another and causes the related images from "disharmony" to "harmony".

The current research on teaching English vignettes using visual teaching methods is still a vacancy. Therefore, this article attempts to carry out related research on visual teaching of English vignettes of students, and hopes to take this opportunity to promote students to master English vignettes better. 


\section{An Empirical Study on the Learnability of Idiomatic Phrases from the Perspective of Cognitive Linguistics}

Prior to the rise of cognitive linguistics, second language acquisition research rarely involved set systems such as idioms, and more attention was paid to the rules system of language. Investigating the reason, we believe that, in theory, it is mainly related to people's understanding of language, and in practice, the guiding ideology of "learning language is to learn grammatical rules and vocabulary" in traditional language teaching has helped fuel the situation. First, the division of labor between syntax rules and terms has always been considered absolute, but as far as idioms that specifically include multiple terms are concerned, those who hold this view feel at a loss. Because chunks have the dual characteristics of syntactic rules and vocabulary, do they belong to the syntax or the terms. Secondly, many people think that figurative language expression is only the embellishment part of the language, so it is not the first task for foreign language learners. Maybe they will not consider quoting from Chen Liang until the learners reach the advanced stage. Third, as mentioned earlier, it is generally believed that the meaning of idioms is unpredictable, their structure is not analyzable, and most of them are conventional, so it is impossible to integrate them into systematic foreign language teaching. The only way to learn them is to memorize them.

A great contribution of cognitive linguistics is that we find that the above-mentioned understanding of idiomatic expressions is one-sided and wrong. On the contrary, this seemingly rigid "death metaphor" is not completely arbitrary, but a system of many concepts. Many cognitive linguists believe that the semantics of most English idioms are analyzable to a certain extent, and that there is a rationale between the metaphorical meaning of idiomatic terms and the literal meaning of their constituent parts. Cognitive linguistics abandons the polarization of syntax rules and morphology, and believes that language is a continuum containing simple to complex language units, and idiomatic words are just one of them. At the same time, the study of metaphor in cognitive linguistics shows that metaphorical language is not the product of the development of language to a certain stage, nor an occasional means of embellishment. They are ubiquitous in daily language use, especially in the expression of abstract concepts, the role of metaphor is irreplaceable.

Unfortunately, although cognitive linguistics has given us a new understanding of idioms, empirical research on idioms in the field of second language acquisition is rare, especially in China's foreign language environment. People are more concerned about how to apply the achievements of cognitive linguistics to foreign language teaching, foreign language idiom dictionary and compilation of textbooks. Therefore, it is necessary for students to find out the cognitive principles and motivations behind their language learning so as to realize the learnability of idioms and promote the effect of foreign language teaching.

\section{Reaching Innovative Teaching Reform with Network and Visual Teaching}

Lack of access to the Internet and inadequate learning facilities such as the use of online autonomous learning centers are important factors restricting students' convenient online autonomous learning. This is a common phenomenon in many universities and a reality that is difficult to change in the short term. Under the existing conditions, how to make full use of the autonomous learning center has become a major problem in using online teaching systems to assist students in autonomous learning. Facing the shortage of autonomous learning equipment on the Internet, under the existing conditions, the only reason is to arrange the opening hours of autonomous learning centers scientifically and reasonably.

According to the author's case investigation, the autonomous learning centers of the schools surveyed currently not only undertake the task of autonomous learning of English, but also the teaching tasks of the school's computer basic courses. For this reason, students' time for learning English in the autonomous learning center is strictly limited. The author suggests whether students can go to the autonomous learning center to study outside of the school's scheduled study time, so that they can win more opportunities for students to study freely. In addition, the school can arrange for an autonomous university English learning platform to be opened during the winter and summer vacations, so that 
students with conditions can study at home. In short, try to provide students with comprehensive learning conditions for autonomous learning under the limited network equipment.

\subsection{Teaching Management Problem Solving}

Teaching management is the process of planning, organizing, controlling, and supervising teaching work in accordance with teaching rules and characteristics. The main contents are six aspects: according to the national teaching plan and syllabus requirements, formulate and implement the school's teaching work plan, specifically implement the curriculum setting, schedule arrangement and class time allocation, and organize guidance, inspection and urge the entire school teachers and students to implement carefully. Establish and improve the teaching management system, in order to achieve teaching goals, put forward functional requirements and assessment standards for teaching management institutions at all levels, clarify the responsibilities and interrelationships of teaching management staff at all levels, and arrange teaching according to different grades, different teaching stages and their characteristics activity. Strengthen the management of teachers' teaching quality and students' learning quality. Go deep into the front line of teaching, focus on the entire teaching process, check the quality of teaching, study the laws of teaching management, summarize and exchange experience in deepening teaching reform, and solve various problems that affect the improvement of teaching quality. Draw up multi-level and multi-type teaching quality assessment indicators. Carry out educational administration work. Reasonable teaching management is of great significance to the quality of talent training in universities. English online self-study has just started in our country, and it requires sound network teaching management to ensure the smooth development of English online autonomy learning.

The specific contents that need to be improved to improve the teaching management of English online autonomous learning are:

1. Develop and implement an English online independent teaching plan. Based on the "Curriculum Requirements" and the actual situation of the school, the school should formulate an independent online English teaching plan suitable for the school.

2. Establish and improve the network teaching management system. In order to achieve English online teaching goals, functional requirements and assessment standards are put forward for relevant levels of teaching management institutions, and the responsibilities and interrelationships of teaching management staff at all levels are clarified.

3. Quantitative management of online teaching work for English teachers. That is to put forward quality standards and specific quantitative requirements for teachers' network teaching thoughts, network teaching skills, network teaching work attitude and network tutoring, network hosting forums, network communication with students, answering student doubts, uploading English materials and network teaching research.

4. Regularly check the quality of online self-study in English. The leaders and departments responsible for teaching in the School of Foreign Languages should regularly or irregularly check the English online teaching of teachers and students. Organize teacher-student communication to eliminate various factors that affect the quality of English online autonomous learning.

5. Develop multi-level and multi-type learning assessment indicators. Put forward clear requirements and specific, feasible, and verifiable assessment methods for students' English learning objectives, attitudes, goals, and planning, interaction and other learning activities in the learning process.

6. Bring English online learning into credit system management. Reform the current method of college English credit measurement and incorporate online course learning into credits.

\subsection{Teacher Problem Solving}

In the modern teaching environment, the material conditions of teaching have changed, and higher requirements have been placed on the quality of teachers. The application of multimedia and network technology in English teaching is not only an update of teaching methods, but also an all-round reform of teaching ideas, teaching concepts, teaching models, and teaching methods. To this end, teachers are no longer just carriers and imparters of language knowledge. They must also have information-based teaching theories and technologies to guide students' online self-learning, answer student doubts, and enable students to learn English independently. Therefore, teachers must not only have solid language 
ontology knowledge, but also have practical knowledge and conditional knowledge in network teaching, but also have advanced educational concepts, excellent teaching monitoring ability and teaching behavior.

Education concept is the psychological background of teachers engaged in education. Teachers' perceptions affect their perceptions and judgments, which in turn affect their teaching behaviors. English teachers' attitudes towards language learning are very important because teachers have a strong influence on the learning environment. Teachers' attitudes and attitudes towards language learning and the teaching methods used are closely related to the effects of teaching and the cultivation of learner abilities. To this end, schools can organize English teachers to learn the latest "Trial Requirements for Teaching College English Courses" issued by the Ministry of Education. Make teachers clarify the teaching nature, teaching goals, teaching requirements, curriculum settings, teaching models, and teaching evaluation of college English after the reform, so that teachers can keep up with the pace of teaching reform.

College English teachers must clearly recognize that college students have at least years of English learning experience, master the most basic vocabulary and grammar knowledge, and have a degree from language learning to consciously learning and using language. At the same time, with the application of computer network technology, teachers' teaching has been greatly extended in time and space. Teachers can teach both in and out of class. Therefore, the focus of English teaching has also changed from how to teach to how to train students to learn independently. Teachers' main responsibilities are to provide students with guidance on course selection, guidance on learning methods, guidance on the use of Internet media, and psychological counseling.

This requires a fundamental change in college English teachers' understanding of online language learning. In English online autonomous learning, teachers are no longer carriers and imparters of language knowledge. They must also have information-based teaching theories and technologies to guide students' autonomous online learning, answer student doubts, and enable students to eventually learn English independently.

To this end, teachers need to change roles. In addition to guiding learning methods and strategies, they must also create conditions for autonomous learning for students, provide guidance on the use of online platforms, and communicate with students through network communication, after-school tutoring, and organizational learning experiences. The online self-study of learning is supervised, inspired students' creative thinking, stimulated their enthusiasm for learning, and encouraged and supported students. At the same time, we must find ways to provide students with a variety of media teaching materials and self-test materials suitable for autonomous learning. Under the new teaching model, teachers will assume important roles such as student mentors, promoters of meaning construction, designers and navigators of information resources, group collaborators, student advisors, researchers and learners.

The teacher's teaching behavior plays a key role in teaching. Whether a teacher's teaching effect is good or bad depends entirely on whether the teaching behavior is reasonable or not.

First of all, teachers should be trained in the basic skills of online teaching. Only by mastering the basic theories and skills can teachers be proficient in using modern teaching methods, thereby forming the driving ability of English online teaching.

Second, improve the theory of teachers' network teaching. The basic theories of network teaching mainly include English teaching theory in the information age, network learning theory, network courses and teaching theory, network education communication theory, technical foundation and art foundation. The basic skills of network teaching mainly include multimedia technology, database technology, and communication technology.

In short, teachers are the key to the success or failure of English online teaching. It is recommended that schools make a long-term and specific plan for teacher training, which must be planned by the school's specialized department and a certain amount of capital investment.

\subsection{Student Problem Solving}

The Presidential Committee of information literacy under the American Library Association formally defines information literacy as a person with information literacy. He must be able to determine when information is needed, and have the ability to retrieve, evaluate and effectively use the required 
information. The ability of network learning is the precondition of students' network self-learning. Teachers should attach importance to the cultivation of students' network learning ability.

The language knowledge and skills uploaded by the teacher in the classroom cannot be fully grasped by the students immediately. The students need a process of self-study and consolidation, and continuous self-drilling can fully absorb the input in the classroom. Moreover, the limited language input in the classroom and textbooks is far from enough for students to truly master a foreign language. They must learn to accept more language input outside the classroom and find more opportunities to use the language. For this reason, the college English online teaching system provides a good platform for students to practice independently. However, in order for students to learn autonomously and effectively, teachers need to teach students online autonomous learning strategies.

Time management strategy is an effective self-learning strategy, which includes setting schedules, setting goals, and adjusting work schedules. Time management strategies are particularly important in online learning. Students often get lost in the face of complicated information on the Internet, and time is fleeting. For this reason, the establishment of an online autonomous learning schedule is an effective guarantee for improving online autonomous learning and reaching the stated learning goals. In time selfmanagement, self-monitoring is an important element. Autonomous learning becomes possible only when individuals monitor themselves. There are significant differences in time management among students of different learning levels. Teachers can help students design a self-monitoring schedule of homework tasks, planned time, start time, completion time, real use time, time utilization rate, extension, shortening, cause analysis and self-evaluation from Monday to Sunday, so as to strengthen self-management of learning time.

Effort management strategies include performance attribution, mood adjustment, introspection, selfreinforcement, and perseverance. These are all related to the psychological factors of the learner and are closely related to the learning motivation of the learner. Achievement attribution is the judgment of attribution of good or bad performance. Different attributions stimulate or weaken motivation to varying degrees. Teachers should cultivate students' habit of finding the cause of success and failure, mainly from their own efforts and learning methods, so that whether they succeed or fail will further strengthen the motivation for learning. On the contrary, at any time, the reasons are attributed to external reasons such as good luck or difficulty of the problem, but they can not stimulate themselves.

To adjust the mood of students and enhance their sense of learning ability, that is, to make students think that they have the ability to master knowledge. If students think that their learning ability is strong, then their confidence is sufficient and their motivation is strong, otherwise they are weak. Students should set appropriate goals in their studies and strive to achieve them through hard work. In this way, each success will increase confidence in your own learning ability, and will strengthen learning motivation. The greater the students' motivation for learning, the more time they spend on learning, and the greater their determination to work hard.

Constantly encourage yourself and strengthen learning. If students learn a course well, they are easy to have interest in it, and they are more interested in it, that is to say, they strengthen their motivation for learning, and they will spend more time to learn, learn more attentively, and learn more effectively, so they are more interested in it, forming a virtuous circle. Therefore, when students are learning difficulties, they must encourage themselves to overcome them and persist. Once the achievement is achieved, it is easy to generate interest in learning and enhance the motivation of learning.

Cultivate perseverance in learning and improve students' knowledge values. If students think that the courses they have learned are valuable, their desire to learn is strong. Students should consciously recognize the meaning and value of the courses they have learned, often remind themselves or write a motto, and encourage themselves to study persistently. The unique information transmission advantage of the network learning environment makes it not only a learning tool, but also an intermediary for communication. It can provide different views and opinions among learners, learners and teachers in the network environment. Opportunities provide a good platform for students to learn independently and need support from others. To this end, learners can seek the help of teachers, partners, and groups in the online learning environment through network communication tools, and get individual and other support guidance. At the same time, teachers can organize partner groups to learn to promote the needs of learners.

The method of strategy training can refer to and put forward the training mode. The teacher introduces a certain learning strategy, explains its essentials and important role. Under the guidance of 
the teacher, the teacher helps the students to consolidate the strategy, so that they can know when and when to use the strategy independently. The students can promote the strategy to other types of language in business or learning activities. In autonomous learning under multimedia network, learners can choose their favorite strategies freely, and at the same time, they can constantly use and expand their own strategies in ordinary learning. Teachers can provide targeted strategy guidance and training to students of different language levels in the class, and constantly strengthen the learned strategies while completing the daily teaching tasks.

The sense of ownership refers to the feeling that learners regulate self-learning. This feeling is a sense of responsibility and obligation established through meaningful goals, expected changes, and their own learning process. Building students' sense of ownership can be done in three ways:

First, enhance students' sense of autonomy. Psychological research shows that the learning behavior of learners is governed by consciousness, so learners must first have a strong desire to learn English, generate motivation from their subjectivity, and then be able to put it into action. It can be seen that the learner's language learning concepts and attitudes are very important before online autonomous learning.

Second, clarify the goals of college English online learning. Let students learn the "Course Requirements", clarify the country's teaching requirements for college English, the general goals that college students should achieve in English learning, and the goals of online English learning, so that students know how much vocabulary they need to master at the university stage What level of competence should the English internet platform play in assisting students' autonomous learning of English in listening and speaking? Then the teacher guides the students to link the goals in the "Course Requirements" with their own needs, and set up specific, detailed, and scientific short-term goals for English learning, so that students feel that learning is to achieve their goals, and they should bear the responsibility of learning.

Third, establish a cooperative learning system for autonomous learning groups. Collaborative learning emphasizes personal responsibility, and requires each member of the cooperative learning group to ensure that they have mastered what is taught. Students are required to be responsible not only for their own learning, but also for the learning of other members of the group. In the network teaching environment, the methods and ways for students to receive knowledge have been greatly expanded. In the face of digital learning resources, in order to strengthen the self-discipline of students' autonomous learning, and to promote the learning interaction between teachers and students, it is suggested to set up a learning group of cooperative learning in groups of around people, and adopt a consultative cooperative learning mode of autonomous learning and cooperation with people.

\section{Conclusion}

The traditional teaching point of view is that there is no close relationship between the meaning of English phrasal verbs and its constituents, and to master them only through repeated memory. This study is based on the theory of cognitive metaphors, and focuses on the small words in phrasal verbs. Starting from the spatial meaning of the small words, it explores their metaphorical meanings to help students better understand and use English phrasal verbs, thereby improving students' comprehensive Language skills. The study found that by explaining and using metaphors, students' abstract thinking ability can be expanded and their metaphor consciousness can be enhanced. Human cognitive ability is constantly improving, and here metaphor plays a catalytic role. Metaphor is a means of forming abstract thinking by knowing the unknown, unfamiliar with the familiar metaphor, complex with the simple metaphor, abstract with the concrete metaphor, and science with the popular metaphor. Metaphor makes most of the abstract thinking possible. The stage of higher education is the period when students' abstract thinking is developing rapidly. Therefore, when teaching English phrase verbs, if you can consciously use cognitive metaphor theory to strengthen the study of metaphorical meaning of sketch words, you can Constantly enhance students' metaphor awareness, thereby greatly improving their ability to understand and use English verbs.

Phrasal verbs are the basic vocabulary in English, and they appear to be spoken in style. They make the language vivid, vivid, and highly expressive. However, for Chinese students, it is a big problem to learn English vocabulary, especially a large number. The metaphorical phrasal verb is not a semantic 
superposition of its components, and students will encounter many difficulties in understanding. However, the traditional English phrase verb teaching emphasizes too much the meaning of verbs and the surface meaning of phrases, and to a certain extent ignores the metaphorical meaning of phrase verbs.

This study uses cognitive metaphor theory to study the teaching of English phrasal verbs. By analyzing the metaphorical meaning of vignettes and metaphorical information in different contexts, students can be more confident in their semantic understanding and use of contexts. Therefore, in daily English teaching activities, metaphor should be used as a cognitive strategy to fully mobilize the enthusiasm and initiative of students, and constantly enhance students' metaphor awareness. The application of cognitive metaphor theory to English teaching can be started from the following aspects:

First, introduce students to some basic cognitive metaphor theories, such as the nature of metaphors, the schema structure of metaphors, and the creativity of metaphors, etc., and help them gradually establish a metaphorical perspective and guide them to understand the meaning of vocabulary from a metaphorical perspective. The semantic relationship between them gradually changes the previous rote memorization method to achieve the purpose of mastering vocabulary and using it flexibly, and finally promotes the comprehensive development of students' comprehensive language use ability.

Second, familiarize students with the cultural background of English-speaking countries. Cognitive metaphor theory holds that language is a way of expressing human thought. Because there are many similarities between human's basic life needs, social activities and understanding of nature, there must be many similarities in metaphors between different nations. Metaphor is also a cultural phenomenon, which largely reflects the cultural model of a nation. Students sometimes find it difficult to understand the metaphors that are very common in English, because they are not familiar with the target domain corresponding to a source domain in their own national thinking and cultural model, or it is difficult to understand it. Therefore, to improve students' metaphor consciousness, we must compare the metaphors of different cultures at home and abroad, and strengthen the learning and understanding of the cultural background of English-speaking countries.

Thirdly, it provides students with plenty of opportunities for language practice. This research only starts with the analysis of sketch words and extends its spatial meaning to metaphorical meanings in different contexts to help students better understand and use English phrase verbs. In ordinary teaching practice, you can also fully explore the profound connotations of idioms and fixed expressions in English, such as everyday expressions, popular sayings, idioms and allusions, guide students to understand their metaphorical meanings, and deepen students' understanding of vocabulary, phrases, and sentences. This is more important because it can improve students' ability to recognize English vocabulary through analysis and understanding of metaphorical meanings, and promote students to effectively use sentences with metaphorical meanings in daily communication, thereby cultivating students' language practice and innovation ability.

Acknowledgements. This paper is supported by the Henan Social Science Federation Project (SKL$2019-2208)$.

\section{References}

1. K Nassaji H, Tian J (2010), "Collaborative and individual output tasks and their effects on learning English phrasal verbs," Language teaching research, vol. 14, no. 4, pp. 397-419.

2. Liu D (2011), "The most frequently used English phrasal verbs in American and British English: A multicorpus examination," Tesol quarterly, vol. 45, no. 4, pp. 661-688.

3. Yasuda S (2010), "Learning phrasal verbs through conceptual metaphors: A case of Japanese EFL learners," Tesol quarterly, vol. 44, no. 2, pp. 250-273.

4. White B J (2012), "A conceptual approach to the instruction of phrasal verbs," The modern language Journal, vol. 96, no. 3, pp. 419-438.

5. Garnier M, Schmitt N (2015), "The PHaVE List: A pedagogical list of phrasal verbs and their most frequent meaning senses," Language teaching research, vol. 19, no. 6, pp. 645-666.

6. Vasbieva D G (2015), "Teaching strategy on learning of English phrasal verbs by economics major students in Russia," XLinguae, vol. 8, no. 3, pp. 57-65. 
7. Mahpeykar N, Tyler A (2015), "A principled cognitive linguistics account of English phrasal verbs with up and out," Language and cognition, vol. 7, no. 1, pp. 1-35.

8. Chen M (2013), "Overuse or underuse: A corpus study of English phrasal verb use by Chinese, British and American university students," International journal of corpus linguistics, vol. 18, no. 3, pp. 418-442.

9. Pasban M A, Forghani M, Nouri A (2015), "The effects of using English captions on Iranian intermediate EFL students learning of phrasal verbs," Journal of language teaching and research, vol. 6, no. 2, pp. 373-382.

10. Zarifi A, Mukundan J (2012), "Phrasal verbs in Malaysian ESL textbooks," English language teaching, vol. 5, no. 5, pp. 9-18.

11. Ahmadi F B, Panahandeh E (2016), "The role of input-based and output-based language teaching in learning English phrasal verbs by upper-intermediate Iranian EFL learners," Journal of education and learning, vol. 10, no. 1 , pp. 22-33.

12. Akbary M, Shahriari H, Hosseini Fatemi A (2018), "The value of song lyrics for teaching and learning English phrasal verbs: a corpus investigation of four music genres," Innovation in language learning and teaching, vol. 12, no. 4, pp. 344-356.

13. Varlamova E V, Naciscione A, Tulusina E A (2016), "A study on the phenomenon of collocations: Methodology of teaching English and German collocations to Russian students," International journal of environmental and science education, vol. 11, no. 6, pp. 1275-1284. 